\title{
Posttraumatic Stress Disorder and Cardiometabolic Disease
}

\author{
Arlene Bradley Levine $^{a} \quad$ Lionel M. Levine $^{b} \quad$ T. Barry Levine ${ }^{a}$ \\ ${ }^{a}$ ABLE Medical Consulting, Pittsburgh, Pa., and ${ }^{b}$ Center for Veterans Enterprise Transformation, Center for \\ Transforming Health, MITRE Corporation, Bedford, Mass., USA
}

\section{Key Words}

Cardiovascular disease - Hypothalamic-pituitary-adrenal axis · Inflammation - Insulin resistance $\cdot$ Metabolism .

Sympathetic nervous system

\begin{abstract}
The need for addressing posttraumatic stress disorder (PTSD) among combat veterans returning from Afghanistan and Iraq is a growing public health concern. Current PTSD management addresses psychiatric parameters of this condition. However, PTSD is not simply a psychiatric disorder. Traumatic stress increases the risk for inflammation-related somatic diseases and early mortality. The metabolic syndrome reflects the increased health risk associated with combat stress and PTSD. Obesity, dyslipidemia, hypertension, diabetes mellitus, and cardiovascular disease are prevalent among PTSD patients. However, there has been little appreciation for the need to address these somatic PTSD comorbidities. Medical professionals treating this vulnerable population should screen patients for cardiometabolic risk factors and avail themselves of existing preventive diet, exercise, and pharmacologic modalities that will reduce such risk factors and improve overall long-term health outcomes and quality of life. There is the promise that cardiometabolic preventive therapy complementing psychiatric intervention may, in turn, help improve the posttraumatic stress system dysregulation and favorably impact psychiatric and neurologic function.

(c) 2013 S. Karger AG, Basel
\end{abstract}

\section{Introduction}

Exposure to traumatic stressors is widespread. Shortterm severe traumatic stress may severely compromise an individual's long-term psychological health. However, there is increasing evidence that posttraumatic stress disorder (PTSD) is not just a 'mental illness' but is also associated with an increased risk for somatic diseases and early mortality $[1,2]$.

Current management of PTSD focuses on the psychiatric parameters of this condition with little emphasis on addressing the comorbid cardiometabolic risk factors that impair overall long-term health outcomes.

\section{Posttraumatic Stress Disorder}

PTSD is a severely disabling neuropsychiatric anxiety disorder that develops in civilians, police officers, combat soldiers, and others as a result of experiencing horrifying trauma/stress [3].

\section{History}

Combat-related stress responses have been mentioned as early as in the 19th century BCE by an Egyptian named Hori, in the 5th century BCE by the Greek historian Herodotus [4], and in the 11th century by the Anglo-Saxon Chronicle [5]. Lady Percy's soliloquy in Henry IV, written around 1597, appears to describe PTSD symptoms

\section{KARGER}

E-Mail karger@karger.com

www.karger.com/crd
(C) 2013 S. Karger AG, Basel

0008-6312/14/1271-0001\$39.50/0
Dr. T. Barry Levine

ABLE Medical Consulting

5622 Bartlett Street

Pittsburgh, PA 15217 (USA)

E-Mail TBLevine6000@yahoo.com 
[6]. During the siege of Gibraltar in 1727, a soldier's diary made note of affected soldiers killing or wounding themselves [5].

Different names have described this condition. In the 17th century, Swiss and German military physicians found soldiers to be suffering from 'nostalgia' and 'Heimweh', respectively. In the early 19th century, military doctors diagnosed battle-stressed soldiers with 'exhaustion'. Civil War combatants suffered from 'soldier's heart'. During the Russo-Japanese War (1905-1906), battle stress was treated as a mental disease. World War I had many soldiers disabled by 'railway spine', 'stress syndrome', 'traumatic war neurosis', or 'shell shock'. Following prolonged combat, enlisted men suffered 'battle fatigue' in World War II and a 'gross stress reaction' during the Korean War. The modern understanding of PTSD evolved as a result of the 'post-Vietnam syndrome' or 'stress response syndrome' experienced by Vietnam veterans in the 1970s, largely due to the efforts of groups, such as the Vietnam Veterans against War working in conjunction with psychiatrist Dr. Chaim F. Shatan. The Diagnostic and Statistical Manual (DSM) of Mental Disorders III incorporated PTSD as a psychiatric diagnosis in $1980[5,7]$.

\section{PTSD Diagnosis}

The 4 th edition of the DSM of Mental Disorders (text rev., DSM-IV-TR) [8] has several criteria for the diagnosis of PTSD, encompassing

(1) A: trauma history;

(2) B-D: behavioral PTSD symptom clusters: intrusion (B), avoidance (C), and arousal (D);

(3) E: duration, and

(4) F: severity.

- Criterion A: prior exposure to traumatic events, a sine qua non for PTSD diagnosis [9].

Such trauma, as distinguished from ordinary stress, posed a perceived physical threat to life or the physical integrity of oneself or others and may range from a

- one-time catastrophic event, to

- chronic severe stresses.

Examples are

- combat- or war-related trauma;

- torture;

- physical and sexual abuse;

- natural disasters;

- criminal or terrorist physical violence;

- exposure to atrocities or their sequelae, or

- overwhelming untreated pain.

- A2: an individual's emotional response at the time.
During the trauma event, the affected individual must have experienced intense

- fear;

- helplessness, or

- horror.

- B: intrusion symptoms.

Emotionally intrusive hypermnesia of the trauma manifests via one or more of the following:

- flashback memories;

- subjective reexperiencing of the traumatic event(s);

- recurring distressing dreams, or

- intense negative psychological or physiological response to any subjective or objective reminder of the traumatic event(s).

- C: avoidance and emotional numbing. This involves a sufficient level and frequency of

- avoidance of any trauma-related stimulus since the associated, aroused feelings are overwhelming;

- avoidance of any trauma reminders that might evoke disturbing memories; flashbacks, nightmares, or intense psychological and physiological distress;

- inability to recall major parts of the trauma;

- decreased capacity, down to complete inability, to experience certain feelings, due to numbness, detachment, or lack of emotion;

- withdrawal and estrangement from family and friends;

- abusive 'self-medication' via alcohol/drugs, and

- an expectation that one's future will be constrained relative to that of others [10].

- D: increased arousal and reactivity.

These are new-onset cognitive, emotional, behavioral, and physiological issues, including

- impaired concentration and memory;

- persistent anxiety, phobic reactions;

- feeling 'on guard', hypervigilance;

- hyperactivity, obsession;

- excessive physical reactivity, increased startle reactions;

- irritability, anger with outbursts;

- physiologic symptoms of autonomic hyperarousal, and

- insomnia $[3,11]$.

- E: duration.

Symptom duration $>1$ month.

- F: symptom impact.

Symptoms must be clinically significantly distressing or impair important life functions, such as social relations and occupational activities, for example $[12,13]$.

The composition and severity of PTSD symptoms vary among individuals. Established PTSD symptomatology can fluctuate over time, often in response to life stresses $[14,15]$. 


\section{Complex PTSD}

The 'simple' PTSD diagnosis may not fully capture the severe psychological symptoms that may arise in survivors of prolonged, repeated, severe trauma lasting months to years. Examples of such trauma include:

- concentration or prisoner-of-war (POW) camps;

- political torture;

- long-term domestic violence;

- long-term physical and/or sexual child abuse;

- prostitution/brothels, or

- organized child exploitation rings [16].

The concept of complex PTSD was first described by Herman [17] who described this aspect of the spectrum of traumatic disorders which may present with multiple symptoms, excessive somatization, dissociation, affect changes, and pathological changes in relationships and in self-identity.

Traumatic Brain Injury

A companion condition to PTSD, traumatic brain injury (TBI), is also a mental health problem, given the large number of soldiers wounded in improvised explosive device attacks. The term describes a range of injuries from mild concussions to severe, penetrating head wounds. Described by Bhattacharjee [18] as 'shell shock revisited', the condition presents itself in similar ways to PTSD. US military service members are returning from the wars in Iraq and Afghanistan with elevated rates of TBI and PTSD. Nineteen percent of returning service members, a total of about 320,000, report that they experienced a possible TBI while deployed, with 7\% reporting both probable TBI and concurrent PTSD or major depression $[19,20]$.

\section{Evolutionary Context}

Mammals, as prey, have evolved to acutely appraise the degree to which a threat taxes their resources. They respond with physiological reactions, including increased heart rate and blood pressure. They react emotionally with fear, terror, or anger. They embrace a range of defensive behaviors as a function of the proximity of the threat, including vigilance, avoidance, withdrawal, aggressive defense, appeasement, or tonic immobility. Cognitively, mammals may respond with dissociation or with heightened memorization of the threat in order to avoid similar threats in the future [21].

Bracha [21] has posited that PTSD may reflect ongoing overactivation of these mammalian threat responses. PTSD-related trauma hypermnesia relates to threat memorization; PTSD-related hyperarousal reflects hypervigilance and aggressive defense under threat, and PTSD-re- lated avoidance behaviors may correspond to mammalian avoidance of, and withdrawal from, threats. Complex PTSD may, in part, correspond to the appeasement and, possibly, the tonic immobility stage $[21,22]$.

\section{Diagnostic Assays}

Several validated trauma assessments allow quantification of trauma symptomatology via clinician-administered symptom checklists or patient self-report [7].

PTSD can be assessed using the Clinician-Administered PTSD Scale, the Short PTSD Rating Interview, the Mississippi Scale for Combat-Related PTSD, the Watson PTSD Inventory, the Computerized Diagnostic Interview Schedule for DSM-IV, the PTSD Checklist and the PTSD Checklist-Military Version, or the Keane PTSD scale. High PTSD symptomatology can be defined via a high Impact of Event Scale score $\geq 26$ compared to $<26$ for low PTSD symptomatology [23].

\section{Course of PTSD}

PTSD can be categorized into

- acute (symptoms lasting 1-3 months), and

- chronic (symptoms persisting $>3$ months) [24]. PTSD onset can be

- early (the majority of PTSD cases developing shortly after the experienced traumatic event);

- delayed (4-6\% of trauma victims develop PTSD months, years, or even decades later), and

- slowly developing (gradual emergence of symptoms that progressively escalate with the passage of time, most likely in response to further traumatizing stressors) [24].

PTSD may go into partial remission; however, there may be long-lasting alterations of the primary stress pathways of the hypothalamic-pituitary-adrenal (HPA) axis and the sympathetic nervous system (SNS), as well as changes in the brain, even after clinical symptoms have subsided. Reexposure to reminders of the original trauma, or to recurrent trauma, may trigger reemergence of the same problems, or increase PTSD symptom severity, due to underlying neuroplastic and cognitive changes $[25,26]$.

\section{Incidence of PTSD}

Up to $50-90 \%$ of humans will experience trauma in their lifetime [27]. Most individuals exposed to comparable trauma are resilient and do not develop PTSD [7].

During the early hours and days following a highly traumatizing event, the majority of people experience at least some symptoms of an acute stress disorder. Although 20-30\% may develop PTSD-like symptoms, more 
than half of such trauma survivors completely recover within 1-3 months in the absence of any intervention [24]. Seven to $12 \%$ of PTSD-afflicted individuals fail to recover without therapy $[27,28]$.

PTSD affects at least 13 million Americans. According to the US National Comorbidity Survey Replication, the adult PTSD lifetime prevalence was approximately $6.8 \%$ [29]. The Wave 2 National Epidemiologic Survey on Alcohol and Related Conditions found a prevalence of $4.5 \%$ [30]. The variability in PTSD prevalence reports may, in part, arise as a function of the reported functional impairment.

As elucidated in a 2011 study from the Georgia State University and San Diego State University, people currently most at risk for developing PTSD are Army and Marine military/combat servicemen exposed to a high operation tempo and tours of duty exceeding a year [31].

In a recent study by the Department of Veterans Affairs (VA), close to $30 \%$ of 834,463 Iraq/Afghanistan veterans seen at VA facilities had PTSD [32], and PTSD rates among these veterans may reach approximately 35\% [33].

Nonmilitary individuals at risk for developing PTSD are Holocaust survivors, victims of war, natural disasters, or criminal/terrorist attacks, or rape/child abuse victims. Twelve to $15 \%$ of patients with acute coronary syndromes (ACS) or myocardial infarctions (MI) develop PTSD as a result of their ACS event [34]. Even elephants, dogs, rats, and other mammals experience PTSD.

PTSD was originally thought to be an ordinary reaction to an extraordinary event, attributing the cause for this disorder to environmental factors, as stated by the psychiatrist and concentration camp survivor Victor Frankl: 'an abnormal response to an abnormal situation is normal behavior'. A subsequent emphasis on vulnerability/resiliency factors suggested that genetic factors dominated the expression of the disorder. For example, the reported prevalence of PTSD tends to be twice as common in women compared to men $[7,35]$. Most likely, a balance between nature and nurture underlies the development of PTSD [36].

\section{Costs of PTSD}

PTSD carries a devastating toll. The individual may be plagued by waking nightmares and insomnia, and succumb to alcoholism, drug abuse, and suicidal thoughts. PTSD is associated with marked deficits in social functioning, disrupting families and relationships. Hyperarousal can impair concentration and occupational performance. The inability to hold a job contributes to an epidemic of homelessness among combat veterans.
The societal toll associated with PTSD entails economic costs due to lost productivity, work absenteeism, suicide, and increased mental health care costs [24]. A RAND study noted that the societal costs of PTSD and major depression for 2 years after deployment range from about 6,000 to $>25,000$ USD/case. The total PTSD- and major depression-related costs for the US in 2007 may range from 4.0 to 6.2 billion USD over 2 years [19]. The societal cost of caring for veterans with stress-related mental health disorders is expected to surpass that of the Global War on Terror, which is estimated at 600 billion USD [37].

\section{PTSD and Health}

\section{Mental Health}

PTSD is associated with poor mental health, including elevated odds of lifetime mood, anxiety, borderline, and narcissistic personality disorders, drug and alcohol use, and decreased psychosocial functioning. PTSD is often accompanied by other comorbid anxiety disorders and depression [30].

\section{Neurological Changes}

PTSD is associated with long-lasting dysregulation of neural networks involved in stress responsivity, learning, and memory $[7,38]$. There is chronic sympathetic and renin-angiotensin-aldosterone system (RAAS) hyperarousal,

- glutamatergic excitotoxicity,

- alterations in neuropeptide Y (NPY), the neuroactive glucocorticoid systems, and brain-derived neurotrophic factor (BDNF), and

- underactivity of the parasympathetic, serotonergic, dopaminergic, and GABAergic system, the primary inhibitory neurotransmitter system,

which all contribute to neurometabolic changes, synaptic loss, neuronal dysfunction, and loss, engendering structural brain changes $[39,40]$.

Brain imaging studies reveal marked reductions in gray matter volumes in memory-/anxiety-relevant brain regions, such as the hippocampus, insula, orbito-/prefrontal cortex, anterior cingulate gyrus, and caudate in PTSD patients $[41,42]$.

The limbic-neuronal structural abnormalities contribute to cognitive/emotional/behavioral symptoms and disorders $[39,40]$. They may underlie the pathophysiology of PTSD and exist on a continuum with PTSD symptoms [43]. 
Pain Syndrome

PTSD victims experience an enhanced rate of chronic pain [26], including headaches, and back, neuropathic [44], and temporomandibular joint pain [45]. Pain and PTSD involve similar brain regions - the amygdala, hippocampus, insula, and the anterior cingulate gyrus. As in anxiety dysregulation, deficient extinction rather than enhanced acquisition of pain responses is a core deficit [26].

\section{Physical Health}

After controlling for major depression, alcohol, nicotine, and substance abuse/dependence, PTSD-affected individuals have a higher incidence of various disorders, including

- increased waist-hip ratio, obesity, hypertension, dyslipidemia, cardio- and cerebrovascular disease, tachycardia, metabolic syndrome, noncirrhotic liver disease, diabetes mellitus (DM), and premature death;

- impaired immunity with increased susceptibility to infections, stomach ulcers, and human immunodeficiency virus seropositivity;

- autoimmune conditions, such as rheumatoid arthritis, psoriasis, and thyroid disease, and

- chronic pain, fibromyalgia, chronic fatigue syndrome, chronic musculoskeletal disorders, bone demineralization, and osteoarthritis [2, 46-50].

\section{PTSD-Related Risk Factors for Cardiometabolic Disease}

PTSD arises in response to overwhelming external stress, but it engenders tremendous ongoing internal distress [49]. Chronic exposure to PTSD-stress-related biochemical pathways accelerates physiologic aging that underlies an increased risk for age-related diseases and early mortality [45].

In a vicious circle, the systemic trauma/stress manifestations may further worsen stress-related structural and functional CNS changes.

\section{Cellular Processes}

PTSD-related cellular dysfunction may arise from stress-induced dysregulation of telomere/telomerase maintenance [39], mitochondria, and endoplasmic reticular (ER) stress.

Telomere Dysfunction

Shalev et al. [51] have undertaken pivotal studies suggesting that stress accelerates telomere erosion beginning very early in life and highlighting the linkage of stress and mental illnesses with telomere erosion. PTSD-stress-related accelerated cell aging is indexed by telomere attrition [52]. Telomerase activity under stress can be low, accentuating telomere loss and stress-related replicative senescence [53]. PTSD patients have shorter age-adjusted leukocyte telomere lengths than controls $[54,55]$.

\section{Mitochondrial Dysfunction}

Work in animal models has shown that exposure to chronic mild stress inhibits mitochondrial respiration rates and dissipates mitochondrial membrane potential [56]. Mitochondria are highly susceptible to damage due to their finite DNA and protein repair mechanisms. Chronically activated stress pathways elicit a prooxidant and proinflammatory milieu that accelerates not only telomere attrition but also mitochondrial dysfunction. Failing mitochondria contribute to cell dysfunction by inducing

- a bioenergetic deficit,

- oxidative stress, and

- a proinflammatory state.

Impaired mitochondrial performance leads to cell senescence and cell death processes. The cumulative cellular losses provoke organ dysfunction, organismal aging, and age-dependent cardiometabolic diseases [57].

\section{ER Stress}

Stress-related mitochondrial dysfunction is intimately linked to ER stress, allowing for deleterious crosstalk between both organelles.

ER stress leads to the misfolding of nascent proteins and the accumulation of such unfolded proteins in the ER lumen. ER stress also promotes chronic oxidative stress $[58,59]$ and inflammatory and degenerative processes, leading to cell pathology, apoptotic cell death, tissue dysfunction, and age-related cardiometabolic diseases [57].

\section{Neuroendocrine Activation}

PTSD-related neurohormonal activation affects not only structural/functional brain changes but also systemic metabolism.

\section{Glucocorticoids}

In a challenge to traditional stress research findings, Yehuda [60] noted that urinary and plasma cortisol levels were considerably lower in PTSD patients than in nonPTSD trauma survivors and normal controls. There is enhanced inhibition of the HPA axis in PTSD patients [41], and both hypocortisolism [46] and reduced responsive- 
ness to glucocorticoids are found in PTSD victims [61]. Hypocortisolism is characterized by a symptom triad of

- pain,

- fatigue, and

- enhanced stress sensitivity [62],

to the extent that low cortisol levels may be a trait that predisposes individuals to the development of PTSD [63]. It may also contribute to alterations in insulin sensitivity [64].

\section{Neurosteroids}

Rasmusson et al. [65] have been involved in pivotal studies on diverse neuroendocrinologic disturbances elicited by PTSD and the link to metabolic syndrome. PTSD is associated with decreased levels of neurosteroids, such as dehydroepiandrosterone (DHEA), allopregnanolone, and pregnanolone, in corticolimbic neurons.

Allopregnanolone and pregnanolone are $3 a$-reduced progesterone derivatives that equipotently and positively modulate the action of GABA at $\mathrm{GABA}_{\mathrm{A}}$ receptors. Since expression of the $3 \alpha$-hydroxysteroid dehydrogenase gene is upregulated by cortisol, PTSD-afflicted individuals with deficient cortisol during stress may not appropriately upregulate allopregnanolone levels. The resulting increased NPY levels have adverse cardiometabolic effects [65].

Increasing DHEA/sulfated DHEA (DHEAS) levels in the face of stress appears to confer psychological resilience, and increased DHEA responses are associated with lower PTSD symptoms [65]. In some individuals, stress may decrease DHEA/DHEAS levels [65], and PTSD victims may have reduced DHEA levels [46]. Low DHEA/ DHEAS levels have been associated with the metabolic syndrome [65].

\section{Sympathetic Arousal}

Kosten et al. [66] noted high urinary norepinephrine/ epinephrine excretion in PTSD patients relative to patients with other mental health diagnoses. There is chronic, high-level SNS arousal in PTSD patients relative to controls, which is evidenced by elevated plasma and 24 -hour urinary catecholamine levels $[67,68]$. PTSD is characterized by tremor and other symptoms of autonomic arousal. PTSD patients exhibit cardiovascular sympathetic activation with significantly higher heart rates and blood pressure levels relative to controls, even during sleep, with lower respiratory sinus arrhythmia $[69,70]$. Corrected for age, PTSD patients, relative to non-trauma-exposed controls, have a high prevalence of lower heart rate variability, consistent with increased sympathetic and attenuated parasympathetic tone at baseline and throughout different affective conditions [71-73].

Sympathetic arousal plays a key role in RAAS activation and the pathogenesis of hypertension, cardiovascular remodeling, and insulin resistance, the magnitude of the sympathetic response to mental stress being associated with increasing insulin resistance. Crosstalk between the catecholamine and insulin signaling pathways establishes the metabolic milieu that blunts insulin sensitivity and is conducive to the development of the metabolic syndrome and type $2 \mathrm{DM}$ in susceptible persons. $\alpha$ - and $\beta$-adrenergic receptor mechanisms are implicated [57].

\section{Neuropeptide Y}

NPY is a sympathetic neurotransmitter involved in stress regulation [74], being anxiolytic and neuroprotective against hippocampal excitotoxicity [75]. It is also involved in learning, memory, and cognition [76].

NPY is released during intense SNS activation. Once released, NPY amplifies norepinephrine effects to increase overall blood pressure while inhibiting vagal action to facilitate stress-related heart rate increases. NPY increases high blood pressure maintenance via mitogenic induction of vascular smooth muscle cell hypertrophy and vasoconstrictor hyperresponsivity to NPY [65].

NPY promotes recovery from stress-induced energy depletion via intracellular, central, and peripheral tissue effects on metabolism and feeding behavior, thus helping to maintain energy balance [74]. Chronic stress-induced NPY release amplifies and accelerates diet-induced obesity and the metabolic syndrome [77].

Male combat veterans with PTSD have reduced resting, as well as stress-activated, plasma NPY levels [78], thus forfeiting its anxiolytic effects. Such individuals, therefore, have a lower stress threshold, paradoxically prompting an increase in the frequency of stress-induced NPY release. In PTSD, lower amplitude NPY stress responses will thus be triggered at higher frequency, not only by exposure to serious stressors in objectively threatening environments, but also repeatedly in reaction to over-generalized, conditioned threat cues in objectively safe environments [65].

In PTSD, the frequency, as well as the amplitude, of NPY release into fat may critically contribute to the risk of developing obesity, hypertension, and the metabolic syndrome [65].

\section{Inflammation}

Multiple factors promote a milieu of systemic inflammation in PTSD. Telomere, mitochondrial, and ER stress 
pathways of cellular senescence promote inflammation [57].

In addition, neuroendocrine and immune systems form an integrated early host response to trauma/stress. PTSD-associated hypocortisolism may fail to contain inflammatory reactions [79], which would, from an evolutionary perspective, foster immune readiness and increased arousal [63]. Since cortisol is normally important for restoring homeostasis after the stress response, insufficient glucocorticoid signaling in PTSD may impair feedback regulation of relevant stress responses, including the SNS [64]. Sympathetic excitotoxicity entails neurogenic priming of the systemic proinflammatory response. PTSD-associated SNS arousal may also activate the RAAS and promote inflammatory pathways [80].

In addition, PTSD stress may alter gene-specific DNA methylation, effecting persistent epigenetic gene function changes, with many of the affected genes being associated with inflammation [81]. Among PTSD patients, the methylation level of such genes is significantly and negatively correlated with trauma/burden [82].

von Känel et al. [83] have been instrumental in elucidating the linkage of PTSD with a proinflammatory state and many of its attendant cardiometabolic sequelae. PTSD patients do have activation of innate immune responses and a low-grade systemic proinflammatory state [84] with increased circulating proinflammatory markers [85] and cytokine serum levels positively related to PTSD scores [86].

Inflammation alters vascular function as well as carbohydrate, protein, and lipid metabolism in order to benefit the host response, but with adverse effects on cardiometabolic health. In order to prioritize energy provisioning to the immune system, proinflammatory cytokines impair non-immune organ insulin sensitivity, engendering insulin resistance. As a result, whereas glucose availability for the insulin-independent immune cells is enhanced, glucose uptake by 'nonessential' insulin-dependent tissues is compromised [57].

Chronic PTSD stress effects may constitute one pathophysiologic link between stress and the development of somatic disorders with an inflammatory etiology, as clustered in cardiometabolic pathologies $[49,64,65,68,87$, 88].

\section{Oxidative Stress}

Mitochondrial dysfunction, ER stress, and RAAS- and inflammation-associated chronic prooxidant stress leads to vascular dysfunction and insulin resistance in a number of tissues, including the vasculature, skeletal and car- diac muscles, fibroblasts, and adipose tissue. Oxidative stress importantly contributes to cardiometabolic disease [57].

\section{Weight Gain}

Stress pathways can induce weight loss due to catabolic and anorexic responses in some individuals [77] but weight gain in others. PTSD groups tend to have an elevated body mass index (BMI) [89].

PTSD is associated with limbic-neuronal structural/ functional abnormalities. Fehm et al. [90] have elucidated central mechanisms of body weight regulation. Hippocampal structures determine the set point for body weight regulation. This hippocampal set point can be permanently displaced by trauma/stress situations. As a result, the energy supply of the stressed organism may predominantly depend on increased new fuel revenue via orexigenic stimuli and metabolic rate dampening rather than on redistributive glucose allocation. This favors stress-induced ponderosity in susceptible individuals and may be a primary disturbance in stress-related obesity [91].

Excess body weight may also stem from a degradation of hippocampal inhibitory learning and memory processes that help regulate energy intake and that normally function to inhibit nonhomeostatic eating behavior [92].

In addition, stress hormone activation significantly reduces food reward sensitivity in the amygdalar/hippocampal/cingulate cortex reward areas. Diminished food reward perception may engender nonhomeostatic consumption of sugar- and fat-rich 'comfort foods' favoring weight gain $[77,93]$.

\section{Obesity}

There is a strong association between PTSD and the risk of central obesity [94]. The prevalence of obesity in the veteran population continues to increase, as documented extensively by Vieweg et al. [95].

In a PTSD program database analysis, the $82.8 \%$ prevalence of overweight/obesity among PTSD veterans (mean BMI $=30.2 \pm 5.8$ ) exceeded the contemporaneous $64.5 \%$ US population findings and those of veteran groups without PTSD [95].

In a sample of randomly selected veterans from the national database, the BMI of male military PTSD veterans ( $\mathrm{n}=1,819$; BMI: $29.28 \pm 6.09)$ exceeded that of nonPTSD veterans ( $\mathrm{n}=44,959 ; 27.61 \pm 5.99 ; \mathrm{p}<0.0001$ ) [96].

In a local database of male military PTSD veterans, mean BMI was in the obese range $(30.00 \pm 5.65)$ and did not vary by age [96] or use of psychotropic drugs associated with weight gain [97]. 
In logistic regression analyses of 20,013 participants weighted to represent the general US adult population, obesity rates were $24.1 \%$ for persons without lifetime PTSD and $32.6 \%$ among persons with PTSD in the past year. After adjustment for sociodemographics, gender, depression, substance and alcohol abuse/dependence, and psychotropic medication status, past-year PTSD was associated with greater likelihood of obesity [odds ratio $(\mathrm{OR})=1.51][98]$.

In multivariate analyses of health information data from 15,000 Gulf War veterans and 15,000 contemporaneous veterans, PTSD was positively associated with obesity after adjustment for age, sex, Gulf deployment status, rank, income, education, and current smoking $(\mathrm{OR}=1.5)$ [99].

In turn, in a survey of 12,992 participants $\geq 16$ years, obesity was significantly associated with PTSD (OR = 2.64) [100].

\section{Insulin Resistance}

PTSD patients have consistent activation of stress pathways. Obesity exacerbates stress activation, facilitating systemic inflammatory activation [91]. As adipose tissue, particularly visceral adiposity, becomes secondarily inflamed and dysfunctional, it amplifies the systemic proinflammatory milieu via massive deleterious systemic free fatty acid and adipocytokine release [57].

Although, in general,

the greater BMI $\rightarrow$ the higher insulin resistance,

adipose inflammation, rather than ponderosity alone, constitutes the link between obesity, insulin resistance, and PTSD-associated cardiometabolic risk [57, 91]. Bays [101] has been at the forefront elucidating the linkage between 'sick fat' (or adiposopathy) and cardiometabolic risk.

In individuals chronically stressed by PTSD, poor health behavior and eating pathology conspire with neuroendocrine mechanisms to promote obesity and attendant cardiometabolic abnormalities [100, 102].

\section{Sleep Debt}

Short sleep duration is associated with symptoms of PTSD, high health risk behaviors, and suicide attempts [103]. PTSD symptom severity is related to the degree of sleep disturbance $[104,105]$. There is fragmentation of rapid eye movement sleep in developing and chronic PTSD and reduced deep slow wave sleep in chronic PTSD [106]. van Liempt et al. [70] and Germain [107] have published extensively on sleep disturbances and PTSD.

\section{Insomnia}

Insomnia is defined as

- an impaired ability to initiate or maintain sleep,

- early awakening, and

- interrupted, nonrestorative, poor-quality sleep,

followed by significantly impaired daytime function not attributable to other conditions [8]. Clinically significant insomnia presents $>3$ times weekly, and chronic insomnia persists for $>6$ months. Insomnia is a core component of PTSD (DSM IV criterion D) [108]. Seventy to $91 \%$ of patients with PTSD report insomnia symptoms. Hyperarousal is a hallmark of PTSD, and insomnia is but a manifestation of continuous PTSD hyperarousal rather than a state of sleep loss [109].

\section{Sleep-Disordered Breathing}

PTSD hyperarousal also appears related to sleep-disordered breathing and impaired sleep maintenance [104, $105,110]$. Sleep-disordered breathing, as well as sleep movement disorders, frequently manifest in PTSD patients at a higher-than-expected prevalence than in the general population $[109,111]$.

\section{Nightmares}

PTSD patients are plagued by posttraumatic traumarelated distressing dreams (DSM IV criterion B) [112]. Nightmares are reported by $19-71 \%$ of PTSD patients, depending on PTSD severity [109]. Dream content may vary between trauma replay, non-replay, or mixed replay/ non-replay, the affect reflecting the terror experienced at the time of trauma [113].

\section{Cardiometabolic Disease}

Chronic sleep loss accelerates age-related chronic cardiometabolic disorders and increases their severity [114]. Epidemiologic studies indicate a causal link between sleep deprivation and

- obesity,

- metabolic syndrome,

- type 2 DM,

- hypertension,

- atherosclerosis,

- stroke,

- heart failure,

- cardiac arrhythmias,

- sudden death, and

- reduced lifespan [57]. 
Worsening PTSD

Sleep problems, especially if associated with nightmares,

- worsen neurocognitive functions,

- negatively impact on PTSD development, severity, and outcome [107],

- adversely affect the efficacy of first-line PTSD treatments [115], and

- are a unique predictor of suicide attempt longitudinally in young military personnel [116].

\section{Metabolic Syndrome}

The metabolic syndrome is defined in an individual by the presence of three out of five modified National Cholesterol Education Program (NCEP): Adult Treatment Panel (ATP) III criteria:

- waist circumference $\geq 102 \mathrm{~cm}$ in men and $\geq 88 \mathrm{~cm}$ in women;

- serum triglycerides (TG) $\geq 150 \mathrm{mg} / \mathrm{dl}$ ( $1.69 \mathrm{mmol} / \mathrm{l}$ );

- high-density lipoprotein (HDL) cholesterol level $<40$ $\mathrm{mg} / \mathrm{dl}(1.04 \mathrm{mmol} / \mathrm{l})$ in men and $<50 \mathrm{mg} / \mathrm{dl}(1.29$ $\mathrm{mmol} / \mathrm{l})$ in women;

- blood pressure $\geq 130 / 85 \mathrm{mmHg}$, and

- serum glucose level $\geq 110 \mathrm{mg} / \mathrm{dl}$ (6.1 mmol/l) [57].

The metabolic syndrome mediates significant longterm health risks. Insulin resistance itself, defined as TG/ $\mathrm{HDL} \geq 3.8$, as well as the metabolic syndrome, is associated with an elevated risk of type $2 \mathrm{DM}$ and cardiovascular disease [117].

The prevalence of insulin resistance, metabolic syndrome, and type $2 \mathrm{DM}$ continues to rise, and nonwhite populations are at the greatest risk. Other contributing factors include mitochondrial dysfunction, aging, chronic infection/inflammation, oxidative stress, inflamed adiposity, physical inactivity, certain medications, genetics, stress, and mental disorders [118]. As noted in a 2006 hearing before the Committee on VA House of Representatives, of the current VA patient population, 2,000,000 have the metabolic syndrome [119].

Traumatic-stress populations display an increased propensity for glucose metabolism disorders [120]. The rate of the metabolic syndrome is especially high among persons with anxiety [121] and psychiatric disorders [122], including PTSD, as outlined in work by Pervanidou and Chrousos [68] as well as Rasmusson et al. [65]. PTSD patients with comorbid depression appear to be at even greater risk for the metabolic syndrome [65, 123].

PTSD and Cardiometabolic Risk

\section{Risk Factors}

The adverse metabolic consequences of the distressaltered HPA, SNS, and RAAS stress responses are additive and complementary. These pathways directly induce insulin resistance.

Trauma/stress pathways impair systemic insulin sensitivity also indirectly via systemic proinflammatory activation and oxidative stress, comorbid inflamed adiposity, posttraumatic insomnia, and sleep-disordered breathing, which facilitate the evolution of insulin resistance and metabolic syndrome in susceptible individuals.

Unhealthy lifestyles prevalent in PTSD compound the development of visceral adiposity, insulin resistance, metabolic syndrome, and DM [89].

In addition, atypical antipsychotics employed for long-term PTSD treatment promote the metabolic syndrome [124]. Among outpatients treated with atypical antipsychotics for various mental health disorders, PTSD patients nevertheless had the highest risk of the metabolic syndrome (72\%) [89].

\section{Prevalence/Incidence}

Metabolic syndrome criteria, albeit prevalent, vary among PTSD patients, suggesting that individually variable neurobiological processes also underlie variations in nonpsychiatric manifestations [65].

In a crossover design study, 15 overweight, male war refugees with PTSD (mean age $44 \pm 11$ years, BMI $29.3 \pm$ 4.3), responded to acute stress exposure with significantly raised postprandial blood glucose and insulin levels [125].

In a cross-sectional survey of 118 active duty, male police officers, those afflicted with PTSD, after controlling for sociodemographics, BMI, and tobacco, alcohol and medication use, exhibited significantly higher serum cholesterol and TG levels than those without PTSD [126].

Among 245 subjects with a low socioeconomic status from medical clinics in Atlanta, the prevalence of the metabolic syndrome was $33.2 \%$, but it was $47.8 \%(\mathrm{p}=0.006)$ among PTSD patients [127].

A peer-reviewed literature search (1966 onward) reported a $31.9-35 \%$ prevalence of the metabolic syndrome in combat PTSD patients [128].

According to the modified NCEP:ATP III criteria, 25$35 \%$ of male PTSD combat veterans had the metabolic syndrome [123, 124, 129].

Forty percent of 253 veterans (average age 51.5 years, 92\% male) at the Cincinnati VA Medical Center met the criteria for the metabolic syndrome, versus $43 \%$ of PTSD veterans $(n=139)$, while controlling for variables includ- 
Table 1. Incidence of insulin resistance and metabolic syndrome with and without PTSD at 2-year follow-up

\begin{tabular}{lccl}
\hline Variable & $\begin{array}{l}\text { PTSD } \\
(\mathrm{n}=11,420)\end{array}$ & $\begin{array}{l}\text { No PTSD } \\
(\mathrm{n}=196,534)\end{array}$ & $\mathrm{p}$ value \\
\hline $\mathrm{TG}, \mathrm{mg} / \mathrm{dl}$ & $139 \pm 90$ & $129 \pm 72$ & 0.001 \\
HDL mg/dl & $42 \pm 15$ & $45 \pm 13$ & 0.006 \\
TG/HDL ratio & $4.3 \pm 3.8$ & $3.3 \pm 1.9$ & 0.0001 \\
Insulin resistance, \% & 34.8 & 19.3 & 0.00001 \\
Fasting blood sugar & $114 \pm 41$ & $110 \pm 38$ & 0.008 \\
Metabolic syndrome & 52.5 & 37.3 & 0.0001 \\
\hline
\end{tabular}

ing sociodemographics, BMI, alcohol/substance/nicotine/medication use, and depression [130].

Ahmadi et al. [131] have shown PTSD to be independently associated with an increased incidence of insulin resistance and metabolic syndrome. In a VA study of electronic medical records of 207,954 veterans in Southern California and Nevada [age $60 \pm 14$ years, $93 \%$ male, no known coronary heart disease (CHD)/DM], there were no significant baseline differences in age, gender, lipids, fasting blood sugar, and conventional risk factors among individuals with and without PTSD. At the 2-year median follow-up, the incidence of insulin resistance, defined as TG/HDL $\geq 3.8$, was higher among PTSD than non-PTSD veterans ( 34.8 vs. $19.3 \%$; $p=0.00001$ ). Similarly, the metabolic syndrome, defined by NCEP:ATP III criteria, was higher among PTSD than non-PTSD veterans (52.5 vs. $37.3 \% ; \mathrm{p}=0.00001$; table 1 ). Adjusted for age, gender, and conventional risk factors, the excess incidence of insulin resistance and metabolic syndrome was 14.20 (17.83$18.53 ; \mathrm{p}=0.0001)$ and $12.07 \%(13.73-14.42 ; \mathrm{p}=0.0001)$ in PTSD veterans and non-PTSD veterans $(\mathrm{p}<0.05)$, respectively. The population risk of insulin resistance and metabolic syndrome attributable to PTSD was 49 and $41 \%$, respectively [131].

\section{PTSD Severity}

The metabolic syndrome and PTSD intensity are significantly related.

After controlling for relevant demographic, somatic, and behavioral/psychiatric factors, veterans with higher PTSD severity were significantly more likely to meet diagnostic criteria for the metabolic syndrome. Each 1-point increase in PTSD symptom severity, as measured by the Clinician-Administered PTSD Scale [132], conferred a 1-point increase in the risk for the metabolic syndrome [130].
The rate of the metabolic syndrome among police officers with the most severe PTSD exceeded that of officers with the lowest PTSD severity category threefold despite adjustments for age and several demographic and lifestyle factors (age, education, smoking, and alcohol intake) [133].

The metabolic syndrome was identified in $66.7 \%$ of high-intensity PTSD combat veterans relative to $23.3 \%$ of low-intensity PTSD veterans [124].

\section{Diabetes Mellitus}

The metabolic syndrome is associated with an elevated risk for DM. Of the current VA patient population, $1,000,000(20 \%)$ veterans have DM. Thirty percent of VA health care costs go to diabetic veterans. As noted by Boscarino [46], PTSD patients, in particular, have an increased risk of insulin-dependent DM.

There is an association between DM and PTSD [134]. In a comparison of 80 PTSD patients and 70 matched non-PTSD controls, PTSD patients had a significantly higher prevalence of fasting blood glucose $>5.6 \mathrm{mmol} / \mathrm{l}$ and DM (26.3 vs. $11.4 \%$; $p<0.05$ ) [135]. In 44,754 military Millennium Cohort Study participants (median age 36 years), after adjustment for age, sex, BMI, education, ethnicity, military service, and mental health, only baseline PTSD symptoms, but not other mental health symptoms or deployment experience, were significantly associated with a future risk of $\mathrm{DM}(\mathrm{OR}=2.07)[136]$. Among low-income minorities with DM, lifetime PTSD symptoms were significantly associated with hemoglobin $\mathrm{A}_{1 \mathrm{C}}$ $>7 \%$ [137].

\section{Neuropathophysiology}

Insulin resistance, metabolic syndrome, and DM, in turn, can worsen structural/functional brain abnormalities in a vicious circle. As pointed out by Reagan [138], Stranahan and Mattson [139] and others [140, 141], there are significant pathophysiological similarities between obesity-/DM-, and stress-related mood disorders. Common mechanisms may include mitochondrial dysfunction, insulin resistance, neuroinflammation, oxidative stress, abnormal brain lipid metabolism, or BDNF deficits. The long-term consequence of both entails accelerated brain aging that increases the risk for psychiatric comorbidities, neurocognitive deficits, and neurodegenerative disorders [142, 143].

The National Comorbidity Survey of US adults (15-54 years) found DM to be associated with an increased likelihood of PTSD $(\mathrm{OR}=2.3)$, which persisted after adjusting for differences in sociodemographics [134].
Levine/Levine/Levine 


\section{Cardiovascular Disease and Mortality}

A number of epidemiologic studies support an association of trauma-/stress-related disorders, including PTSD, with increased cardiovascular risk, hypertension, and CHD [144, 145].

In 2005, the VA affirmed hypertension, atherosclerosis, and stroke to be service connected in former POW [146]. In VA and non-VA healthcare data (1991-2000) for 19,442 former World War II POW and 9,728 nonPOW controls, POW had a significantly higher risk of PTSD, and PTSD POW had significantly higher risks of hypertension and CHD compared to non-POW and nonPTSD POWs [147]. In a review of 11 studies, PTSD patients had increased rates of physician-rated and self-reported cardiovascular diseases [148].

Boscarino [149] and others [131] have brought to the fore the notion that PTSD constitutes a potent risk factor for cardiovascular disease.

\section{Mechanisms}

Trauma-/stress-related anxiety disorders, particularly PTSD, confer SNS hyperarousal, HPA axis dysregulation, proinflammatory activation, obesity, and sleep disturbances, conditions conducive not only to the development of the metabolic syndrome but also of CHD [144, 150].

Inflammation may link PTSD with an increased risk of cardiovascular events [83]. Numerous molecular and cellular proinflammatory pathways promote atherosclerosis [151].

Metabolically, inflammation entails insulin resistance and underlies the development of the metabolic syndrome. The metabolic syndrome constitutes a clustering of cardiovascular risk factors that directly and indirectly hasten cardiovascular disease and predict CHD-related morbidity and premature mortality [152].

\section{Risk Perception}

The association between PTSD and increased cardiometabolic disease is often complicated by a co-occurrence of multiple health risk behaviors or comorbid psychiatric conditions.

Many PTSD patients significantly reduce their sport participation following onset of PTSD symptomatology [153].

The Large Health Survey of Veterans $(\mathrm{n}=501,161)$ showed a statistically increased $(\mathrm{OR}=1.26)$ co-occurrence of obesity, current tobacco use, and absence of regular exercise among PTSD veterans [154]. Among CHD patients, those with PTSD are more likely to report physical inactivity, medication nonadherence, and smoking. Adjustment for comorbid depression and lower income explain some of these associations [155].

ACS patients with PTSD have significantly greater optimistic bias regarding their ability to control their $\mathrm{CHD}$ on their own than do controls after adjustment for demographics, ACS severity, medical comorbidities, depression, and self-confidence [156]. Since patients with PTSD tend to avoid stress, PTSD symptoms among ACS patients are independently associated with significantly longer prehospital delays [157].

Following ACS/MI, PTSD symptoms predict nonadherence to medical advice and treatments, with a higher likelihood of ACS recurrence, cardiovascular morbidity, and readmission during the 1-year follow-up $[156,158]$.

\section{Dyslipidemia}

PTSD may promote an unfavorable lipid profile, specifically low HDL and elevated TG plasma levels comprising two modified NCEP:ATP III metabolic syndrome criteria. Such dyslipidemia may contribute to PTSD-related atherosclerotic risk [159].

In a mouse model with features of PTSD and major depression, a Western-style diet increased non-HDL cholesterol and intrahepatic TG accumulation [160].

In a comparison of 80 PTSD patients and 70 nonPTSD controls, PTSD patients had a higher prevalence of $\mathrm{HDL}<1.0 \mathrm{mmol} / \mathrm{l}(31.3$ vs. $8.6 \% ; \mathrm{p}=0.0006)$ and $\mathrm{TG}>2.3$ $\mathrm{mmol} / \mathrm{l}$ (62.5 vs. $21.4 \% ; \mathrm{p}=0.001)$ [135]. In a comparison of 50 PTSD veterans with non-PTSD veterans, PTSD veterans had lower HDL $(0.96 \pm 0.18$ vs. $1.15 \pm 0.24 \mathrm{mmol} / \mathrm{l}$; $\mathrm{p}<0.001)$ but higher TG $(2.55 \pm 0.68$ vs. $1.73 \pm 0.77$ $\mathrm{mmol} / \mathrm{l} ; \mathrm{p}<0.001)$ [161], with similar findings in other studies [162, 163]. Patients with PTSD caused by MI had significantly lower HDL than patients with subsyndromal or no PTSD after controlling for sex, BMI, and statinequivalent dosage. HDL levels were significantly inversely associated with total PTSD symptoms, reexperiencing, and avoidance [159].

\section{Vascular Dysfunction}

Psychological distress can result in arterial endothelial injury. Inflammation and insulin resistance entail endothelial dysfunction [164].

PTSD has a continuous relationship with indices of endothelial dysfunction, such as soluble tissue factor and von Willebrand factor [165]. PTSD is associated with higher levels of circulating cellular adhesion molecules, greater PTSD severity correlating with significantly high- 
er resting levels of soluble vascular cellular adhesion molecule-1 and soluble P-selectin [166].

In the Buffalo Cardio-Metabolic Occupational Police Stress study of 100 randomly selected police officers, who were compared to similarly aged populations, police officers had higher rates of PTSD, depression, and elevated BMI with lower flow-mediated dilation [167].

PTSD is associated with decreased compliance of large arteries. Pulse wave velocity measures of arterial stiffness increased with PTSD severity $(\mathrm{p}=0.001)$ [135].

In a review of electronic medical records of $896 \mathrm{pa}-$ tients 1 year before until 4 years after the disaster, after adjusting for demographics, smoking, and physical health before the disaster, disaster-related PTSD was significantly associated with newly recorded vascular problems $(\mathrm{OR}=1.92)$ [168].

Erectile dysfunction can be multifactorial and caused by the use psychotropic medications. It is also a symptom of endothelial dysfunction. PTSD is associated with pervasive sexual dysfunction [169]. Erectile difficulties are common among PTSD-afflicted Vietnam veterans [170]. PTSD combat veterans experience a significantly higher rate (85\%) of sexual dysfunction than do non-PTSD veterans (22\%). Moderate-to-severe erectile dysfunction is present in $45 \%$ of PTSD patients versus $13 \%$ of controls [171].

\section{Hypertension}

Vascular dysfunction is a risk factor for hypertension. The prevalence of hypertension, a modified NCEP:ATP III metabolic syndrome criterion, appears to be increased in PTSD $[172,173]$.

Altered neurochemistry, most notably perturbations in norepinephrine and NPY function [78, 174], and increased arginine-vasopressin levels may contribute to hypertension in PTSD [175].

PTSD is characterized by the absence of normal nocturnal blood pressure dipping and elevated nocturnal blood pressure [176]. PTSD patients have significantly higher diastolic blood pressure compared with patients afflicted by other psychiatric disorders [89]. Data from the US National Comorbidity Survey suggest PTSD to be related to hypertension independently of depression [177].

In a comparison of 80 elderly PTSD patients with 70 non-PTSD controls, PTSD patients had a higher prevalence of blood pressure $>140 / 90$ ( 86.0 vs. $65.7 \% ; p=0.003$ ) [135]. In a comparison of 1,381 Gulf War veterans with non-PTSD veterans, adjusted OR for hypertension was 2.90 in the past 12 months and 2.27 for lifetime prevalence in PTSD veterans. Hypertension was $>7$ times more likely among PTSD veterans than among those free of mental illness [178].

\section{Hypercoagulability}

Platelet activation and hypercoagulability occur in the metabolic syndrome and contribute to coronary atherothrombosis.

Platelet reactivity in PTSD may be exaggerated [179] by SNS hyperarousal, and altered adenylate cyclase and platelet $\alpha_{2}$-adrenoreceptor expression [145]. Platelet reactivity was higher in PTSD war veterans than in healthy controls and correlated with the severity of PTSD symptoms [145].

PTSD may elicit subthreshold hypercoagulability [180], but hypercoagulability may become exacerbated by anticipatory stress [181]. PTSD patients are at higher risk of arterial and venous thromboembolic events [181]. Von Willebrand factor antigen levels and factor VIII activity were significantly increased in severe chronic PTSD patients compared to controls [182].

\section{Coronary Heart Disease}

Dyslipidemia, vascular dysfunction, hypertension, and hypercoagulability are all manifestations of the metabolic syndrome that contribute to $\mathrm{CHD}$, a serious comorbidity of the metabolic syndrome.

There is a substantial link between PTSD and CHD. PTSD is a risk factor for atherogenesis and cardiovascular disease $[149,175,183]$.

In a comparison of 50 PTSD veterans with 50 nonPTSD veterans, the 10 -year ATP III CHD risk was higher in the PTSD group $(19.44 \pm 7.27$ vs. $9.74 \pm 4.10 \%$; $\mathrm{p}<$ 0.001) [161]. The 10-year ATP III CHD risk was also higher in 103 combat-related PTSD patients versus 92 depressed patients [163]. Higher measured PTSD symptomatology increases the incident CHD risk. In a study of 179 patients (mean age $=63$ years, $68 \%$ men) with psychotic symptoms but without known $\mathrm{CHD}$ /stroke at baseline, PTSD increased the Framingham 10-year CHD risk by $72 \%$ relative to the general Framingham Heart Study population [184].

PTSD was associated with premature atherosclerosis of coronary, cerebral, and peripheral blood vessels in the veterans of special risk subdivisions [185].

PTSD correlates with the presence and severity of coronary atherosclerosis as reflected by the coronary artery calcium (CAC) score. In a study of 637 veterans without known CHD (61 \pm 9 years, $12.2 \%$ women), CAC was more prevalent in the PTSD cohort than the non-PTSD cohort (76.1 vs. $59 \%$; $\mathrm{p}=0.001$ ), and their CAC scores
Levine/Levine/Levine 
were significantly higher in each Framingham risk score category compared to the non-PTSD group. Multivariable generalized linear regression analysis identified PTSD as an independent predictor of the presence and extent of atherosclerotic CHD $(\mathrm{p}<0.01)$ [186].

In a comparison of 80 PTSD patients with 70 nonPTSD controls, PTSD patients had a higher prevalence of CHD (71.3 vs. $44.3 \%$; $\mathrm{p}<0.001$ ). Stepwise logistic regression showed PTSD to be a strong factor promoting the appearance of CHD (OR 3.80; $\mathrm{p}=0.002$ ) [135].

The prevalence of MI and stroke is increased in PTSD $[172,173,186]$. In a study of 4,462 nonhospitalized male veterans (mean age $=38$ ) about 20 years following military service, after controlling for multiple biases, confounders, current anxiety, and depression, PTSD was significantly associated with resting 12-lead electrocardiographic findings of atrioventricular conduction defects $(\mathrm{OR}=2.81)$ and infarctions $(\mathrm{OR}=4.44)$ [164].

PTSD symptoms occur in $10-25 \%$ of patients presenting with ACS. In turn, PTSD is an important compounding factor for the genesis of future cardiovascular disease [187]. PTSD is prospectively associated with an increased risk of cardiovascular readmission in post-MI patients [148]. In a meta-analysis of 24 studies including 2,383 ACS patients, developing PTSD due to ACS doubled the risk of having recurrent ACS or dying within 1-3 years compared with cardiac patients who did not develop PTSD [188].

\section{Premature Mortality}

PTSD is a risk factor for increased premature mortality independent of age, gender, and conventional risk factors [186]. PTSD is prospectively associated with an increased risk of cardiovascular mortality in combat veterans [148]. PTSD is a strong and independent predictor of an elevated risk for major adverse cardiac events and all-cause mortality (adjusted hazard ratio 3.38; $\mathrm{p}=0.015$ ), and should be considered in ACS patient risk stratification [34].

During a mean follow-up of 42 months of 637 veterans without known CHD (age $=61 \pm 9$ years), the death rate in the PTSD cohort exceeded that of the non-PTSD group ( 17.1 vs. $10.4 \% ; \mathrm{p}=0.003$ ). Multivariable survival regression analyses revealed a significant PTSD mortality and CAC mortality linkage. After adjustment for risk factors, relative risk of death was $1.48(\mathrm{p}=0.01)$ in subjects with PTSD and CAC score $>0$ compared to subjects without PTSD and CAC score $=0$. For each non-zero CAC category, the relative risk of death of PTSD subjects exceeded that of matched non-PTSD subjects (1.23 for CAC scores 1-100, 1.51 for CAC scores 101-400, and 1.81 for CAC scores $\geq 400 ; \mathrm{p}<0.05$ for all comparisons) [186].
PTSD symptoms adversely affect long-term mortality risk in implantable cardioverter-defibrillator (ICD)treated cardiac event survivors, independent of disease severity. In 5.1-year follow-up data derived from the Living with an Implanted Cardioverter-Defibrillator-Study of 211 patients with ICDs, PTSD patients had no differences in left ventricular ejection fraction status or extent of ICD discharges compared with non-PTSD patients. The relative mortality risk (multivariate adjusted for age, sex, DM, left ventricular ejection fraction, $\beta$-blocker prescription, prior resuscitation, ICD shocks received, depression, and anxiety) hazard ratio was $3.45(\mathrm{p}=0.002)$ for the PTSD group [189].

There is also a higher risk of mortality following surgery in PTSD patients $[46,173,190]$.

\section{Sympathetic Activity}

Heart rate variability is reduced with PTSD. Low heart rate variability is a robust predictor of cardiac mortality [191].

In 891 veterans, 91 with PTSD (age $67 \pm 12$ years), presenting for routine echocardiography and followed for $\leq 7.5$ years, midregional proadrenomedullin, a marker of sympathetic activation, was an independent predictor of all-cause mortality after adjusting for B-type natriuretic peptide, cardiovascular risk factors, cancer, and sleep apnea $(\mathrm{p}=0.007)$ [192].

Basal heart rate may be elevated in PTSD, reflecting not only elevated sympathetic but also abnormally low tonic parasympathetic cardiac activity [193]. An elevated resting heart rate is associated with reduced survival [194] and is a risk factor for mortality independent of physical fitness, physical activity, and other major cardiovascular risk factors [195].

\section{Suicide}

PTSD is a major suicide risk factor $[116,196]$, especially if left untreated. PTSD suicidality may be associated with a decrease in BDNF functioning [197].

\section{Conclusion}

The need for addressing PTSD among returning combat veterans is a growing public health concern. Untreated or undertreated PTSD entails a cascading set of problems, with drug use, suicide, marital problems, unemployment, and homelessness being just some of the consequences. 
PTSD is treatable. Current PTSD management addresses psychiatric parameters of this condition primarily via the use of cognitive behavioral therapy in conjunction with available anti-anxiety medications, antidepressants, and antipsychotics, which only partially reduce symptoms.

Efforts are underway both to lower susceptibility to PTSD through greater stress resilience training and to lessen its advent or severity via immediate posttraumatic psychological and pharmacological intervention. Ongoing studies that focus on the (epi)genetic and neurobiologic underpinnings of the stress response may bring about targeted therapies that focus on restoring normal hippocampal function and the extinction of learned fear responses in PTSD, particularly during the posttraumatic neuroplastic 'window of opportunity'.

However, PTSD is not simply a psychiatric disorder. Traumatic stress deleteriously increases the risk for inflammation-related somatic diseases and early mortality, but little emphasis has been placed on addressing these somatic PTSD comorbidities.

PTSD is a substantial risk factor for the metabolic syndrome and cardiovascular disease that warrants increased screening and clinical intervention to predict and prevent the onset of cardiometabolic disease in PTSD patients. Insulin resistance, metabolic syndrome, and $\mathrm{CHD}$ can be reversed during their early stages. Advising patients of existing preventive diet, exercise, and pharmacologic modalities in conjunction with PTSD-related psychiatric therapy will reduce cardiometabolic risk factors to lessen long-term adverse health outcomes, such as DM, heart attack, stroke, and death, and will improve quality of life. Such an approach has been shown to be effective in the management of patients with clinical depression for whom guideline-based, collaborative managed care, aiming to treat depression as well as chronic systemic disease, provided significantly improved control of both medical disease (CHD and/or DM) and depression relative to usual care controls [198].
There is the promise that current cardiometabolic preventive therapy may also help improve the posttraumatic dysregulation of cortical arousal and neurohormonal abnormalities, thus favorably impacting neuropsychologic function:

- Regular physical exercise may enhance executive function, hippocampus-dependent learning and memory, neuroprotection, neurogenesis, synaptic plasticity, neurotransmission, prefrontal cortex blood flow, and hippocampal volume, in part by increasing the expression of BDNF. It may ameliorate PTSD symptomatology.

- Dietary n-3 polyunsaturated fatty acids may protect hippocampal plasticity, help prevent neuroinflammation, and enhance resistance to oxidative stress, while normalizing BDNF levels and improving learning ability, with potential benefit for PTSD symptoms.

- Angiotensin receptor blockers may lower brain inflammation, be neuroprotective, increase BDNF signaling, improve cognition, and decrease PTSD symptomatology.

- Statins may enhance BDNF signaling, induce brain plasticity, and have neuroprotective and neurorestorative effects.

- Metformin may recruit neural stem cells, promote neurogenesis, improve neuronal function, and enhance spatial memory formation.

- Centrally acting $\alpha_{1}$-adrenoceptor antagonists appear promising for their capacity to reduce PTSD-related nightmares and insomnia.

- Successful treatment of sleep-disordered breathing improves insomnia, nightmares, and PTSD symptoms independent of psychiatric interventions.

We have a clear moral duty to ensure that our fighting men and women receive comprehensive care for all the injuries they sustained while serving our nation. Their sacrifices should not be in vain. The therapeutic effort must comprehensively address both psychiatric and cardiometabolic disease. High-quality prevention and treatment could save close to 2 billion USD within 2 years by substantially reducing indirect PTSD costs [19].
References
1 McEwen B: Protective and damaging effects of stress mediators. N Engl J Med 1998;338: 171-179.

2 McFarlane A: The long-term costs of traumatic stress: intertwined physical and psychological consequences. World Psychiatry 2010;9:3-10.

3 Vanitallie T: Stress: a risk factor for serious illness. Metabolism 2002;51(6 suppl 1):40-45.
4 http://ptsd.kpaulmedical.com/2011/04/ahistory-of-ptsd-part-1-a-soldiers-heart/.

5 http://www.vva.org/archive/TheVeteran/2005_03/feature_HistoryPTSD.htm.

6 Trimble M: Post-traumatic stress disorder: history of a concept; in Figley CR (ed): Trauma and Its Wake: The Study and Treatment of Post-Traumatic Stress Disorder. New York, Brunner/Mazel, 1985. 
7 Vermetten E, Lanius R: Biological and clinical framework for posttraumatic stress disorder. Handb Clin Neurol 2012;106:291-342.

8 American Psychiatric Association: Diagnostic and Statistical Manual of Mental Disorders, Fourth Edition, Text Revision: DSM-IVTR. Arlington, American Psychiatric Publishing, 2000.

9 http://www.ptsd.va.gov/professional/pages/ ptsd-overview.asp.

10 Monson C, Fredman S, Macdonald A, PukayMartin N, Resick P, Schnurr P: Effect of cognitive-behavioral couple therapy for PTSD. A randomized controlled trial. JAMA 2012;308: 700-709.

$\checkmark 11$ Khozhenko E: Neuronal mechanisms underlying main clinical syndromes of post-traumatic stress disorder (in Russian). Klin Med (Mosk) 2009;87:4-9.

12 Glass A, Jones F: Psychiatry in the U.S. Army: Lessons for Community Psychiatry. Bethesda, Uniformed Services University of the Health Sciences F. Edward Hébert School of Medicine, 2005.

13 Kaouane N, Porte Y, Vallée M, Brayda-Bruno L, Mons N, Calandreau L, Marighetto A, Piazza P, Desmedt A: Glucocorticoids can induce PTSD-like memory impairments in mice. Science 2012;335:1510-1513.

14 American Psychiatric Association: Diagnostic and Statistical Manual of Mental Disorders, ed 4. Washington, American Psychiatric Association, 1994.

15 McEwen B: The neurobiology and neuroendocrinology of stress. Implications for posttraumatic stress disorder from a basic science perspective. Psychiatr Clin North Am 2002; 25:469-494.

16 Herman J: Trauma and Recovery: The Aftermath of Violence from Domestic Abuse to Political Terror. New York: Basic Books, 1997.

17 Herman J: CPTSD is a distinct entity: comment on Resick et al. (2012). J Trauma Stress 2012;25:256-257.

18 Bhattacharjee Y: Shell shock revisited: solving the puzzle of blast trauma. Science 2008;319: 406-408.

19 Tanielian T, Jaycox L (eds): Invisible Wounds of War. Psychological and Cognitive Injuries, Their Consequences, and Services to Assist Recovery. Santa Monica, RAND, 2008.

20 http://www.rand.org/news/press/2008/04/ 17.html.

-21 Bracha H: Human brain evolution and the 'Neuroevolutionary Time-Depth Principle': implications for the reclassification of fearcircuitry-related traits in DSM-V and for studying resilience to warzone-related posttraumatic stress disorder. Prog Neuropsychopharmacol Biol Psychiatry 2006;30:827-853.

22 Bovin M, Marx B: The importance of the peritraumatic experience in defining traumatic stress. Psychol Bull 2011;137:47-67.
23 Boscarino J, Kirchner H, Hoffman S, Sartorius J, Adams R, Figley C: A brief screening tool for assessing psychological trauma in clinical practice: development and validation of the New York PTSD Risk Score. Gen Hosp Psychiatry 2011;33:489-500.

24 Taylor S: Clinician's Guide to PTSD: A Cognitive-Behavioral Approach. New York, Guilford Press, 2006.

25 Vasterling J, Proctor S, Friedman M, Hoge C, Heeren T, King L, King D: PTSD symptom increases in Iraq-deployed soldiers: comparison with nondeployed soldiers and associations with baseline symptoms, deployment experiences, and postdeployment stress. J Trauma Stress 2010;23:41-51.

26 Flor H: Some thoughts on trauma, pain, posttraumatic stress disorder and traumatic brain injury. J Clin Psychol Med Settings 2011;18: 205-206.

27 Mehta D, Binder E: Gene × environment vulnerability factors for PTSD: the HPA-axis. Neuropharmacology 2012;62:654-662.

-28 Steckler T, Risbrough V: Pharmacological treatment of PTSD - established and new approaches. Neuropharmacology 2012;62:617627.

29 Kessler R, Berglund P, Delmer O, Jin R, Merikangas $\mathrm{K}$, Walters $\mathrm{E}$ : Lifetime prevalence and age-of-onset distributions of DSM-IV disorders in the National Comorbidity Survey Replication. Arch Gen Psychiatry 2005;62:593596.

30 Pietrzak R, Goldstein R, Southwick S, Grant B: Psychiatric comorbidity of full and partial posttraumatic stress disorder among older adults in the United States: results from wave 2 of the National Epidemiologic Survey on Alcohol and Related Conditions. Am J Geriatr Psychiatry 2012;20:380-390.

31 Cesur R, Sabia J, Tekin E: The psychological costs of war: military combat and mental health. J Health Econ 2013;32:51-65.

32 Levy H, Conoscenti L, Tillery J, Dickstein B, Litz B: Deployment stressors and outcomes among Air Force chaplains. J Trauma Stress 2011;24:342-346.

33 Atkinson M, Guetz A, Wein L: A dynamic model for posttraumatic stress disorder among U.S. troops in Operation Iraqi Freedom. Manag Sci 2009;55:1454-1468.

- 34 Edmondson D, Rieckmann N, Shaffer J, Schwartz J, Burg M, Davidson K, Clemow L, Shimbo D, Kronish I: Posttraumatic stress due to an acute coronary syndrome increases risk of 42-month major adverse cardiac events and all-cause mortality. J Psychiatr Res 2011; 45:1621-1626.

35 Bangasser D, Valentino R: Sex differences in molecular and cellular substrates of stress. Cell Mol Neurobiol 2012;32:709-723.

36 Kimble M, Kaufman M: Clinical correlates of neurological change in posttraumatic stress disorder: an overview of critical systems. Psychiatr Clin North Am 2004;27:49-65.
37 Callahan D: Combat-related mental health disorders: the case for resiliency in the long war. J Am Osteopath Assoc 2010;110:520527.

38 Vermetten E, Bremner J: Circuits and systems in stress. I. Preclinical studies. Depress Anxiety 2002;15:126-147.

39 Wolkowitz O, Epel E, Reus V, Mellon S: Depression gets old fast: do stress and depression accelerate cell aging? Depress Anxiety 2010; 27:327-338.

40 Streeter C, Gerbarg P, Saper R, Ciraulo D, Brown R: Effects of yoga on the autonomic nervous system, gamma-aminobutyric-acid, and allostasis in epilepsy, depression, and post-traumatic stress disorder. Med Hypotheses 2012;78:571-579.

41 Li X, Han F, Liu D, Shi Y: Single-prolonged stress induced mitochondrial-dependent apoptosis in hippocampus in the rat model of post-traumatic stress disorder. J Chem Neuroanat 2010;40:248-255.

42 Dannlowski U, Stuhrmann A, Beutelmann $\mathrm{V}$, Zwanzger P, Lenzen T, Grotegerd $\mathrm{D}$ Domschke K, Hohoff C, Ohrmann P, Bauer J, Lindner C, Postert C, Konrad C, Arolt V, Heindel W, Suslow T, Kugel H: Limbic scars: long-term consequences of childhood maltreatment revealed by functional and structural magnetic resonance imaging. Biol Psychiatry 2012;71:286-293.

-43 Herringa R, Phillips M, Almeida J, Insana S, Germain A: Post-traumatic stress symptoms correlate with smaller subgenual cingulate, caudate, and insula volumes in unmedicated combat veterans. Psychiatry Res 2012;203: 139-145

44 Gibson C: Review of posttraumatic stress disorder and chronic pain: the path to integrated care. J Rehabil Res Dev 2012;49:753-776.

45 Uhac I, Tariba P, Kovac Z, Simonić-Kocijan S, Lajnert V, Mesić V, Kuis D, Braut V: Masticatory muscle and temporomandibular joint pain in Croatian war veterans with posttraumatic stress disorder. Coll Antropol 2011; 35:1161-1166.

46 Boscarino J: Posttraumatic stress disorder and physical illness: results from clinical and epidemiologic studies. Ann NY Acad Sci 2004;1032:141-153.

-47 David D, Woodward C, Esquenazi J, Mellman T: Comparison of comorbid physical illnesses among veterans with PTSD and veterans with alcohol dependence. Psychiatr Serv 2004:55: 82-85.

48 McEwen B: Protection and damage from acute and chronic stress: allostasis and allostatic overload and relevance to the pathophysiology of psychiatric disorders. Ann NY Acad Sci 2004;1032:1-7.

49 Rohleder N, Karl A: Role of endocrine and inflammatory alterations in comorbid somatic diseases of post-traumatic stress disorder. Minerva Endocrinol 2006;31:273-288. 
50 Maslov B, Marcinko D, Milicevic R, Babić D, Dordević V, Jakovljević M: Metabolic syndrome, anxiety, depression and suicidal tendencies in post-traumatic stress disorder and schizophrenic patients. Coll Antropol 2009; 33(suppl 2):7-10.

-51 Shalev I, Entringer S, Wadhwa P, Wolkowitz O, Puterman E, Lin J, Epel E: Stress and telomere biology: a lifespan perspective. Psychoneuroendocrinology 2013;38:1835-1842.

52 Puterman E, Lin J, Blackburn E, O’Donovan A, Adler N, Epel E: The power of exercise: buffering the effect of chronic stress on telomere length. PLoS One 2010;5:e10837.

-53 Beery A, Lin J, Biddle J, Francis D, Blackburn E, Epel E: Chronic stress elevates telomerase activity in rats. Biol Lett 2012;8:1063-1066.

54 Malan S, Hemmings S, Kidd M, Martin L, Seedat S: Investigation of telomere length and psychological stress in rape victims. Depress Anxiety 2011;28:1081-1085.

55 O’Donovan A, Epel E, Lin J, Wolkowitz O, Cohen B, Maguen S, Metzler T, Lenoci M, Blackburn E, Neylan T: Childhood trauma associated with short leukocyte telomere length in posttraumatic stress disorder. Biol Psychiatry 2011;70:465-471.

56 Gong Y, Chai Y, Ding J, Sun X, Hu G: Chronic mild stress damages mitochondrial ultrastructure and function in mouse brain. Neurosci Lett 2011;488:76-80.

57 Levine T, Levine A: Metabolic Syndrome and Cardiovascular Disease. Chichester, WileyBlackwell, 2012.

58 Brown M, Naidoo N: The endoplasmic reticulum stress response in aging and age-related diseases. Front Physiol 2012;3:263.

59 Ferreiro E, Baldeiras I, Ferreira I, Costa R, Rego A, Pereira C, Oliveira C: Mitochondrialand endoplasmic reticulum-associated oxidative stress in Alzheimer's disease: from pathogenesis to biomarkers. Int J Cell Biol 2012; 2012:735206.

60 Yehuda R: Biology of posttraumatic stress disorder. J Clin Psychiatry 2001;62(suppl 17):4146.

61 Pace T, Wingenfeld K, Schmidt I, Meinlschmidt G, Hellhammer D, Heim C: Increased peripheral NF- $\mathrm{kB}$ pathway activity in women with childhood abuse-related posttraumatic stress disorder. Brain Behav Immun 2012;26:13-17.

-62 Fries E, Hesse J, Hellhammer J, Hellhammer D: A new view on hypocortisolism. Psychoneuroendocrinology 2005;30:1010-1016.

63 Radley J, Kabbaj M, Jacobson L, Heydendael W, Yehuda R, Herman J: Stress risk factors and stress-related pathology: neuroplasticity, epigenetics and endophenotypes. Stress 2011; 14:481-497.

64 Raison C, Miller A: When not enough is too much: the role of insufficient glucocorticoid signaling in the pathophysiology of stress-related disorders. Am J Psychiatry 2003;160: 1554-1565.
65 Rasmusson A, Schnurr P, Zukowska Z, Scioli E, Forman D: Adaptation to extreme stress: post-traumatic stress disorder, neuropeptide $\mathrm{Y}$ and metabolic syndrome. Exp Biol Med (Maywood) 2010;235:1150-1162.

66 Kosten T, Mason J, Giller E, Ostroff R, Harkness L: Sustained urinary norepinephrine and epinephrine elevation in post-traumatic stress disorder. Psychoneuroendocrinology 1987;12:13-20.

67 Bedi U, Arora R: Cardiovascular manifestations of posttraumatic stress disorder. J Natl Med Assoc 2007;99:642-649.

68 Pervanidou P, Chrousos G: Neuroendocrinology of post-traumatic stress disorder. Prog Brain Res 2010;182:149-160.

-69 Woodward S, Arsenault N, Voelker K, Nguyen T, Lynch J, Skultety K, Mozer E, Leskin G, Sheikh J: Autonomic activation during sleep in posttraumatic stress disorder and panic: a mattress actigraphic study. Biol Psychiatry 2009;66:41-46.

70 van Liempt S, Arends J, Cluitmans P, Westenberg H, Kahn R, Vermetten E: Sympathetic activity and hypothalamo-pituitary-adrenal axis activity during sleep in post-traumatic stress disorder: a study assessing polysomnography with simultaneous blood sampling. Psychoneuroendocrinology 2013;38: 155165.

71 Blechert J, Michael T, Grossman P, Lajtman $\mathrm{M}$, Wilhelm F: Autonomic and respiratory characteristics of posttraumatic stress disorder and panic disorder. Psychosom Med 2007;69:935-943.

72 Tan G, Fink B, Dao T, Hebert R, Farmer L, Sanders A, Pastorek N, Gevirtz R: Associations among pain, PTSD, mTBI, and heart rate variability in veterans of Operation Enduring and Iraqi Freedom: a pilot study. Pain Med 2009;10:1237-1245.

73 Hauschildt M, Peters M, Moritz S, Jelinek L: Heart rate variability in response to affective scenes in posttraumatic stress disorder. Biol Psychol 2011;88:215-222.

-74 Wu G, Feder A, Wegener G, Bailey C, Saxena S, Charney D, Mathé A: Central functions of neuropeptide $\mathrm{Y}$ in mood and anxiety disorders. Expert Opin Ther Targets 2011;15: 1317-1331.

75 Gonçalves J, Ribeiro C, Malva J, Silva A: Protective role of neuropeptide $\mathrm{Y}_{2}$ receptors in cell death and microglial response following methamphetamine injury. Eur J Neurosci 2012;36:3173-3183.

76 Eaton K, Sallee F, Sah R: Relevance of neuropeptide Y (NPY) in psychiatry. Curr Top Med Chem 2007;7:1645-1659.

77 Kuo L, Czarnecka M, Kitlinska J, Tilan J, Kvetnanský R, Zukowska Z: Chronic stress, combined with a high-fat/high-sugar diet, shifts sympathetic signaling toward neuropeptide $\mathrm{Y}$ and leads to obesity and the metabolic syndrome. Ann NY Acad Sci 2008;1148: 232-237.
78 Rasmusson A, Hauger R, Morgan C, Bremner J, Charney D, Southwick S: Low baseline and yohimbine-stimulated plasma neuropeptide Y (NPY) in combat-related posttraumatic stress disorder. Biol Psychiatry 2000;47:526539.

79 Rohleder N, Joksimovic L, Wolf J, Kirschbaum C: Hypocortisolism and increased glucocorticoid sensitivity of pro-inflammatory cytokine production in Bosnian war refugees with posttraumatic stress disorder. Biol Psychiatry 2004;55:745-751.

80 Miksa M, Wu R, Zhou M, Wang P: Sympathetic excitotoxicity in sepsis: pro-inflammatory priming of macrophages by norepinephrine. Front Biosci 2005;10:2217-2229.

81 Smith A, Conneely K, Kilaru V, Mercer K, Weiss T, Bradley B, Tang Y, Gillespie C, Cubells J, Ressler K: Differential immune system DNA methylation and cytokine regulation in post-traumatic stress disorder. Am J Med Genet B Neuropsychiatr Genet 2011; 156B:700-708.

82 Uddin M, Aiello A, Wildman D, Koenen K, Pawelec G, de Los Santos R, Goldmann E, Galea S: Epigenetic and immune function profiles associated with posttraumatic stress disorder. Proc Natl Acad Sci USA 2010;107: 9470-9475.

83 von Känel R, Begré S, Abbas C, Saner H, Gander M, Schmid J: Inflammatory biomarkers in patients with posttraumatic stress disorder caused by myocardial infarction and the role of depressive symptoms. Neuroimmunomodulation 2010;17:39-46.

84 Bauer M, Wieck A, Lopes R, Teixeira A, Grassi-Oliveira R: Interplay between neuroimmunoendocrine systems during post-traumatic stress disorder: a minireview. Neuroimmunomodulation 2010;17:192-195.

85 Baker D, Nievergelt C, O'Connor D: Biomarkers of PTSD: neuropeptides and immune signaling. Neuropharmacology 2012; 62:663-673.

86 Miller R, Sutherland A, Hutchison J, Alexander D: C-reactive protein and interleukin 6 receptor in post-traumatic stress disorder: a pilot study. Cytokine 2001;13:253-255.

87 Leonard B: The HPA and immune axes in stress: the involvement of the serotonergic system. Eur Psychiatry 2005;20(suppl 3):S302-S306.

88 Zunszain P, Anacker C, Cattaneo A, Carvalho L, Pariante C: Glucocorticoids, cytokines and brain abnormalities in depression. Prog Neuropsychopharmacol Biol Psychiatry 2011;35: 722-729.

-89 Jin H, Lanouette N, Mudaliar S, Henry R, Folsom D, Khandrika S, Glorioso D, Jeste D: Association of posttraumatic stress disorder with increased prevalence of metabolic syndrome. J Clin Psychopharmacol 2009;29:210-215.

90 Fehm L, Kern W, Peters A: Body weight regulation through the central nervous system. The development of a pathogenetically based adiposity therapy. Med Klin (Munich) 2004; 99:674-679. 
91 Fehm H, Kern W, Peters A: The selfish brain: competition for energy resources. Prog Brain Res 2006; 153:129-140.

-92 Davidson T, Kanoski S, Walls E, Jarrard L: Memory inhibition and energy regulation. Physiol Behav 2005;86:731-746.

-93 Born J, Lemmens S, Rutters F, Nieuwenhuizen A, Formisano E, Goebel R, WesterterpPlantenga M: Acute stress and food-related reward activation in the brain during food choice during eating in the absence of hunger. Int J Obes (Lond) 2010;34:172-181.

94 Dedert E, Becker M, Fuemmeler B, Braxton L, Calhoun P, Beckham J: Childhood traumatic stress and obesity in women: the intervening effects of PTSD and MDD. J Trauma Stress 2010;23:785-763.

-95 Vieweg W, Julius D, Benesek J, Satterwhite L, Fernandez A, Feuer S, Pandurangi A: Posttraumatic stress disorder and body mass index in military veterans. Preliminary findings. Prog Neuropsychopharmacol Biol Psychiatry 2006;30:1150-1154.

96 Vieweg W, Julius D, Bates J, Quinn JF 3rd, Fernandez A, Hasnain M, Pandurangi A: Posttraumatic stress disorder as a risk factor for obesity among male military veterans. Acta Psychiatr Scand 2007;116:483-487.

$\$ 97$ Vieweg W, Julius D, Fernandez A, Tassone D, Narla S, Pandurangi A: Posttraumatic stress disorder in male military veterans with comorbid overweight and obesity: psychotropic, antihypertensive, and metabolic medications. Prim Care Companion J Clin Psychiatry 2006;8:25-31.

$\$ 98$ Pagoto S, Schneider K, Bodenlos J, Appelhans B, Whited M, Ma Y, Lemon S: Association of post-traumatic stress disorder and obesity in a nationally representative sample. Obesity (Silver Spring) 2012;20:200205.

$\checkmark 99$ Coughlin S, Kang H, Mahan C: Selected health conditions among overweight, obese, and non-obese veterans of the 1991 Gulf War: results from a survey conducted in 2003-2005. Open Epidemiol J 2011;4:140146.

100 Scott K, McGee M, Wells J, Oakley Browne $\mathrm{M}$ : Obesity and mental disorders in the adult general population. J Psychosom Res 2008; 64:97-105.

101 Bays H: 'Sick fat', metabolic disease, and atherosclerosis. Am J Med 2009; 122(suppl 1):S26-S37.

102 Pervanidou P, Chrousos G: Metabolic consequences of stress during childhood and adolescence. Metabolism 2012;61:611-619.

103 Luxton D, Greenburg D, Ryan J, Niven A, Wheeler G, Mysliwiec V: Prevalence and impact of short sleep duration in redeployed OIF soldiers. Sleep 2011;34:1189-1195.

104 Krakow B, Melendrez D, Warner T, Dorin R, Harper R, Hollifield M: To breathe, perchance to sleep: sleep-disordered breathing and chronic insomnia among trauma survivors. Sleep Breath 2002;6:189-202.
05 Babson K, Feldner M, Badour C, Trainor C, Blumenthal H, Sachs-Ericsson N, Schmidt $\mathrm{N}$ : Posttraumatic stress and sleep: differential relations across types of symptoms and sleep problems. J Anxiety Disord 2011;25: 706-713.

106 Kobayashi I, Cowdin N, Mellman T: One’s sex, sleep, and posttraumatic stress disorder. Biol Sex Differ 2012;3:29.

107 Germain A: Sleep disturbances as the hallmark of PTSD: where are we now? Am J Psychiatry 2013;170:372-382.

108 Mellman T, Knorr B, Pigeon W, Leiter J, Akay M: Heart rate variability during sleep and the early development of posttraumatic stress disorder. Biol Psychiatry 2004;55: 953-956.

109 Maher M, Rego S, Asnis G: Sleep disturbances in patients with post-traumatic stress disorder: epidemiology, impact and approaches to management. CNS Drugs 2006;20:567590.

110 Krakow B, Melendrez D, Warner T, Clark J, Sisley B, Dorin R, Harper R, Leahigh L, Lee S, Sklar D, Hollifield M: Signs and symptoms of sleep-disordered breathing in trauma survivors: a matched comparison with classic sleep apnea patients. J Nerv Ment Dis 2006; 194:433-439.

111 Brown T, Boudewyns P: Periodic limb movements of sleep in combat veterans with posttraumatic stress disorder. J Trauma Stress 1996;9:129-136.

112 Nappi C, Drummond S, Hall J: Treating nightmares and insomnia in posttraumatic stress disorder: a review of current evidence. Neuropharmacology 2012;62:576-585.

113 Phelps A, Forbes D, Hopwood M, Creamer M: Trauma-related dreams of Australian veterans with PTSD: content, affect and phenomenology. Aust NZ J Psychiatry 2011;45: 853-860.

114 Swanson L, Favorite T, Horin E, Arnedt J: A combined group treatment for nightmares and insomnia in combat veterans: a pilot study. J Trauma Stress 2009;22:639-642.

115 Belleville G, Guay S, Marchand A: Persistence of sleep disturbances following cognitive-behavior therapy for posttraumatic stress disorder. J Psychosom Res 2011;70: 318-327.

116 Ribeiro J, Pease J, Gutierrez P, Silva C, Bernert R, Rudd M, Joiner TJ: Sleep problems outperform depression and hopelessness as cross-sectional and longitudinal predictors of suicidal ideation and behavior in young adults in the military. J Affect Disord 2012; 136:743-750.

117 Jeppesen J, Hansen T, Rasmussen S, Ibsen H, Torp-Pedersen C, Madsbad S: Insulin resistance, the metabolic syndrome, and risk of incident cardiovascular disease: a population-based study. J Am Coll Cardiol 2007;49: 2112-2119.
118 Norris J, Rich S: Mechanisms and consequences: genetics of glucose homeostasis: implications for insulin resistance and metabolic syndrome. Arterioscler Thromb Vasc Biol 2012;32:2091-2096.

119 US Government Printing Office: Hearing to Review the Department of Veterans Affairs Medical and Prosthetic Research Program. Washington, US Government Printing Office, 2007.

120 Cohen H, Kozlovsky N, Savion N, Matar M, Loewenthal U, Loewenthal N, Zohar J, Kaplan Z: An association between stress-induced disruption of the hypothalamic-pituitary-adrenal axis and disordered glucose metabolism in an animal model of posttraumatic stress disorder. J Neuroendocrinol 2009;21:898-909.

121 Luppino F, van Reedt Dortland A, Wardenaar K, Bouvy P, Giltay E, Zitman F, Penninx B: Symptom dimensions of depression and anxiety and the metabolic syndrome. Psychosom Med 2011;73:257-264.

122 Heiskanen T, Niskanen L, Hintikka J, Koivumaa-Honkanen $\mathrm{H}$, Honkalampi $\mathrm{K}$, Haatainen K, Viinamaki H: Metabolic syndrome and depression: a cross-sectional analysis. J Clin Psychiatry 2006;67:1422-1427.

123 Jakovljević M, Babić D, Crncević Z, Martinac M, Maslov B, Topić R: Metabolic syndrome and depression in war veterans with post-traumatic stress disorder. Psychiatr Danub 2008;20:406-410.

124 Babić D, Jakovljević M, Martinac M, Sarić M, Topić R, Maslov B: Metabolic syndrome and combat post-traumatic stress disorder intensity: preliminary findings. Psychiatr Danub 2007;19:68-75.

125 Nowotny B, Cavka M, Herder C, Löffler H, Poschen U, Joksimovic L, Kempf K, Krug A, Koenig W, Martin S, Kruse J: Effects of acute psychological stress on glucose metabolism and subclinical inflammation in patients with post-traumatic stress disorder. Horm Metab Res 2010;42:746-753.

126 Maia D, Marmar C, Mendlowicz M, Metzler T, Nóbrega A, Peres M, Coutinho E, Volchan E, Figueira I: Abnormal serum lipid profile in Brazilian police officers with posttraumatic stress disorder. J Affect Disord 2008; 107:259-263.

127 Weiss T, Skelton K, Phifer J, Jovanovic T, Gillespie CF, Smith A, Umpierrez G, Bradley B, Ressler KJ: Posttraumatic stress disorder is a risk factor for metabolic syndrome in an impoverished urban population. Gen Hosp Psychiatry 2011;33:135-142.

128 Jakovljević M, Crncević Z, Ljubicić D, Babić D, Topić R, Sarić M: Mental disorders and metabolic syndrome: a fatamorgana or warning reality? Psychiatr Danub 2007;19:76-86.

129 Jakovljevic M, Saric M, Nad S, Topic R, Vuksan-Cusa B: Metabolic syndrome, somatic and psychiatric comorbidity in war veterans with post-traumatic stress disorder: preliminary findings. Psychiatr Danub 2006;18: 169-176. 
130 Heppner P, Crawford E, Haji U, Afari N, Hauger R, Dashevsky B, Horn P, Nunnink S, Baker D: The association of posttraumatic stress disorder and metabolic syndrome: a study of increased health risk in veterans. BMC Med 2009;7:1.

131 Ahmadi N, Arora R, Yehuda R, Ebrahimi R: Post-traumatic stress disorder is associated with increased incidence of insulin resistance and metabolic syndrome. J Am Coll Cardiol 2013;61(10_S), DOI: $10.1016 /$ S0735-1097(13)61347-9.

132 Weathers FW, Keane TM, Davidson JR: Clinician-administered PTSD scale: a review of the first ten years of research. Depress Anxiety 2001;13:132-156.

-133 Violanti JM, Fekedulegn D, Hartley TA, Andrew ME, Charles LE, Mnatsakanova A, Burchfiel CM: Police trauma and cardiovascular disease: association between PTSD symptoms and metabolic syndrome. Int J Emerg Ment Health 2006;8:227-237.

134 Goodwin R, Davidson J: Self-reported diabetes and posttraumatic stress disorder among adults in the community. Prev Med 2005;40:570-574.

135 Walczewska J, Rutkowski K, Wizner B, Cwynar M, Grodzicki T: Stiffness of large arteries and cardiovascular risk in patients with post-traumatic stress disorder. Eur Heart J 2011;32:730-736.

-136 Boyko E, Jacobson I, Smith B, Ryan M, Hooper T, Amoroso P, Gackstetter G, Barrett-Connor E, Smith T, Millennium Cohort Study Team Collaborators: Risk of diabetes in U.S. military service members in relation to combat deployment and mental health. Diabetes Care 2010;33:1771-1777.

137 Miller S, Mancuso C, Boutin-Foster C, Michelen W, McLean-Long C, Foote B, Charlson $\mathrm{M}$ : Associations between posttraumatic stress disorder and hemoglobin $\mathrm{A} 1(\mathrm{C})$ in low-income minority patients with diabetes. Gen Hosp Psychiatry 2011;33:116-122.

138 Reagan L: Insulin signaling effects on memory and mood. Curr Opin Pharmacol 2007; 7:633-637.

139 Stranahan A, Mattson M: Bidirectional metabolic regulation of neurocognitive function. Neurobiol Learn Mem 2011;96:507516.

140 Yates K, Sweat V, Yau P, Turchiano M, Convit $A$ : Mechanisms and consequences: impact of metabolic syndrome on cognition and brain: a selected review of the literature. Arterioscler Thromb Vasc Biol 2012;32: 2060-2067.

141 Ye X, Tai W, Zhang D: The early events of Alzheimer's disease pathology: from mitochondrial dysfunction to BDNF axonal transport deficits. Neurobiol Aging 2012;33: 1122.e1-1122e10.

142 Wada A, Yokoo H, Yanagita T, Kobayashi $\mathrm{H}$ : New twist on neuronal insulin receptor signaling in health, disease, and therapeutics. J Pharmacol Sci 2005;99:128-143.
143 Martín E, Sánchez-Perez A, Trejo J, MartinAldana J, Cano JM, Pons S, Acosta UC, Menes L, White M, Burks D: IRS-2 deficiency impairs NMDA receptor-dependent long-term potentiation. Cereb Cortex 2012;22:1717-1727.

144 Player M, Peterson L: Anxiety disorders, hypertension, and cardiovascular risk: a review. Int J Psychiatry Med 2011;41:365-377.

145 Vidović A, Grubišić-Ilić M, Kozarić-Kovačić D, Gotovac K, Rakoš I, Markotić A, Rabatić S, Dekaris D, Sabioncello A: Exaggerated platelet reactivity to physiological agonists in war veterans with posttraumatic stress disorder. Psychoneuroendocrinology 2011; 36:161-172.

146 Department of Veterans Affairs: Presumptions of service connection for diseases associated with service involving detention or internment as a prisoner of war. Affirmation of interim final rule as final rule. Fed Regist 2005;70:37040-37042.

147 Kang H, Bullman T, Taylor J: Risk of selected cardiovascular diseases and posttraumatic stress disorder among former World War II prisoners of war. Ann Epidemiol 2006;16: 381-386.

148 Gander M, von Känel R: Myocardial infarction and post-traumatic stress disorder: frequency, outcome, and atherosclerotic mechanisms. Eur J Cardiovasc Prev Rehabil 2006; 13:165-172.

149 Boscarino J: PTSD is a risk factor for cardiovascular disease: time for increased screening and clinical intervention. Prev Med 2012;54:363-364.

150 Kibler J: Posttraumatic stress and cardiovascular disease risk. J Trauma Dissociation 2009;10:135-150.

151 Libby P: History of discovery: inflammation in atherosclerosis. Arterioscler Thromb Vasc Biol 2012;32:2045-2051.

152 Rask-Madsen C, Kahn C: Mechanisms and consequences: tissue-specific insulin signaling, metabolic syndrome, and cardiovascular disease. Arterioscler Thromb Vasc Biol 2012;32:2052-2059.

153 de Assis M, de Mello M, Scorza F, Cadrobbi M, Schooedl A, Gomes da Silva S, de Albuquerque M, da Silva A, Arida R: Evaluation of physical activity habits in patients with posttraumatic stress disorder. Clinics (Sao Paulo) 2008;63:473-478.

154 Chwastiak L, Rosenheck R, Kazis L: Association of psychiatric illness and obesity, physical inactivity, and smoking among a national sample of veterans. Psychosomatics 2011; 52:230-236.

155 Zen A, Whooley M, Zhao S, Cohen B: Posttraumatic stress disorder is associated with poor health behaviors: findings from the heart and soul study. Health Psychol 2012; 31:194-201.

156 Edmondson D, Shaffer J, Denton E, Shimbo D, Clemow L: Posttraumatic stress and myocardial infarction risk perceptions in hospitalized acute coronary syndrome patients. Front Psychol 2012;3:144.
157 Newman J, Muntner P, Shimbo D, Davidson K, Shaffer J, Edmondson D: Post-traumatic stress disorder (PTSD) symptoms predict delay to hospital in patients with acute coronary syndrome. PLoS One 2011;6:e27640.

158 Shemesh E, Yehuda R, Milo O, Dinur I, Rudnick A, Vered Z, Cotter G: Posttraumatic stress, nonadherence, and adverse outcome in survivors of a myocardial infarction. Psychosom Med 2004;66:521-526.

159 Von Känel R, Kraemer B, Saner H, Schmid J, Abbas C, Begré S: Posttraumatic stress disorder and dyslipidemia: previous research and novel findings from patients with PTSD caused by myocardial infarction. World J Biol Psychiatry 2010;11:141-147.

160 Chuang J, Cui H, Mason B, Mahgoub M, Bookout A, Yu H, Perello M, Elmquist J, Repa J, Zigman J, Lutter M: Chronic social defeat stress disrupts regulation of lipid synthesis. J Lipid Res 2010;51:1344-1353.

161 Dzubur Kulenović A, Kucukalić A, Malec D: Changes in plasma lipid concentrations and risk of coronary artery disease in army veterans suffering from chronic posttraumatic stress disorder. Croat Med J 2008;49:506514.

162 Karlović D, Martinac M, Buljan D, Zoricić Z: Relationship between serum lipid concentrations and posttraumatic stress disorder symptoms in soldiers with combat experiences. Acta Med Okayama 2004;58:23-27.

163 Solter V, Thaller V, Karlović D, Crnković D: Elevated serum lipids in veterans with combat-related chronic posttraumatic stress disorder. Croat Med J 2002;43:685-689.

164 Boscarino J, Chang J: Electrocardiogram abnormalities among men with stress-related psychiatric disorders: implications for coronary heart disease and clinical research. Ann Behav Med 1999;21:227-234.

165 von Känel R, Hepp U, Traber R, Kraemer B, Mica L, Keel M, Mausbach B, Schnyder U: Measures of endothelial dysfunction in plasma of patients with posttraumatic stress disorder. Psychiatry Res 2008;158:363-373.

166 von Känel R, Abbas C, Begré S, Saner H, Gander M, Schmid J: Posttraumatic stress disorder and soluble cellular adhesion molecules at rest and in response to a traumaspecific interview in patients after myocardial infarction. Psychiatry Res 2010;179: 312-317.

167 Violanti J, Burchfiel C, Miller D, Andrew M, Dorn J, Wactawski-Wende J, Beighley C, Pierino K, Joseph P, Vena J, Sharp D, Trevisan M: The Buffalo Cardio-Metabolic Occupational Police Stress (BCOPS) pilot study: methods and participant characteristics. Ann Epidemiol 2006;16:148-156.

168 Dirkzwager A, van der Velden P, Grievink L, Yzermans C: Disaster-related posttraumatic stress disorder and physical health. Psychosom Med 2007;69:435-440. 
169 Reznik I, Zemishlany Z, Kotler M, Spivak B, Weizman A, Mester R: Sildenafil citrate for the sexual dysfunction in antidepressanttreated male patients with posttraumatic stress disorder. A preliminary pilot openlabel study. Psychother Psychosom 2002;71: 173-176.

170 Kaplan P: Post-traumatic stress syndrome and sexual dysfunction. J Sex Marital Ther 1989;15:74-77.

171 Cosgrove D, Gordon Z, Bernie J, Hami S, Montoya D, Stein M, Monga M: Sexual dysfunction in combat veterans with post-traumatic stress disorder. Urology 2002;60:881884.

172 Brass L, Page W: Stroke in former prisoners of war. J Stroke Cerebrovasc Dis 1996;6:7278.

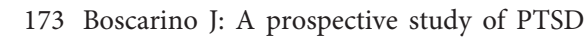
and early-age heart disease mortality among Vietnam veterans: implications for surveillance and prevention. Psychosom Med 2008; 70:668-676.

174 Kuo L, Kitlinska J, Tilan J, Li L, Baker S, Johnson M, Lee E, Burnett M, Fricke S, Kvetnansky R, Herzog H, Zukowska Z: Neuropeptide $Y$ acts directly in the periphery on fat tissue and mediates stress-induced obesity and metabolic syndrome. Nat Med 2007;13: 803-811.

$\checkmark 175$ Wentworth B, Stein M, Redwine L, Xue Y, Taub P, Clopton P, Nayak K, Maisel A: Posttraumatic stress disorder: a fast track to premature cardiovascular disease? Cardiol Rev 2013;21:16-22.

-176 Mellman T, Brown D, Jenifer E, Hipolito M, Randall O: Posttraumatic stress disorder and nocturnal blood pressure dipping in young adult African Americans. Psychosom Med 2009;71:627-630.

177 Kibler J, Joshi K, Ma M: Hypertension in relation to posttraumatic stress disorder and depression in the US National Comorbidity Survey. Behav Med 2009;34:125-132.

178 Abouzeid M, Kelsall H, Forbes A, Sim M, Creamer M: Posttraumatic stress disorder and hypertension in Australian veterans of the 1991 Gulf War. J Psychosom Res 2012; 72:33-38.
179 Montoro-García S, Shantsila E, Lip G: Platelet reactivity in prolonged stress disorders a link with cardiovascular disease? Psychoneuroendocrinology 2011;36:159-160.

180 von Känel R, Hepp U, Buddeberg C, Keel M, Mica L, Aschbacher K, Schnyder U: Altered blood coagulation in patients with posttraumatic stress disorder. Psychosom Med 2006; 68:598-604.

181 von Känel R, Abbas C, Schmid J, Saner H, Haeberli A, Stutz M, Begre S: Momentary stress moderates procoagulant reactivity to a trauma-specific interview in patients with posttraumatic stress disorder caused by myocardial infarction. J Psychiatr Res 2010; 44:956-963.

182 Robicsek O, Makhoul B, Klein E, Brenner B, Sarig G: Hypercoagulation in chronic posttraumatic stress disorder. Isr Med Assoc J 2011;13:548-552.

183 Coughlin S: Post-traumatic stress disorder and cardiovascular disease. Open Cardiovasc Med J 2011;5:164-170.

184 Jin H, Folsom D, Sasaki A, Mudaliar S, Henry R, Torres M, Golshan S, Glorioso D, Jeste D: Increased Framingham 10-year risk of coronary heart disease in middle-aged and older patients with psychotic symptoms. Schizophr Res 2011;125:295-299.

185 Alishev N, Drabkin B, Shubik V: Stress-immunity-health (problem of premature aging in veterans of special risk subdivisions). Adv Gerontol 2010;23:49-55.

186 Ahmadi N, Hajsadeghi F, Mirshkarlo H, Budoff M, Yehuda R, Ebrahimi R: Post-traumatic stress disorder, coronary atherosclerosis, and mortality. Am J Cardiol 2011;108: 29-33.

187 Cotter G, Milo-Cotter O, Rubinstein D, Shemesh E: Posttraumatic stress disorder: a missed link between psychiatric and cardiovascular morbidity? CNS Spectr 2006;11: 129-136.

188 Voelker R: Study: acute coronary events linked with PTSD. JAMA 2012;308:121.

189 Ladwig K, Baumert J, Marten-Mittag B, Kolb C, Zrenner B, Schmitt C: Posttraumatic stress symptoms and predicted mortality in patients with implantable cardioverter-defibrillators: results from the prospective living with an implanted cardioverter-defibrillator study. Arch Gen Psychiatry 2008;65:13241330 .
190 Brzezinski M, Marmar C, Cason B, Au S, Wallace A: Diagnosis of PTSD is associated with 1- and 5-year mortality. Annual Meeting of the American Society of Anesthesiologists, New Orleans, 2009.

191 Kemp A, Quintana D, Felmingham K, Matthews S, Jelinek H: Depression, comorbid anxiety disorders, and heart rate variability in physically healthy, unmedicated patients: implications for cardiovascular risk. PLoS One 2012; 7:e30777.

192 Xue Y, Taub P, Iqbal N, Fard A, Wentworth B, Redwine L, Clopton P, Stein MMA: Cardiac biomarkers, mortality, and post-traumatic stress disorder in military veterans. Am J Cardiol 2012;109:1215-1218.

193 Hopper J, Spinazzola J, Simpson W, van der Kolk B: Preliminary evidence of parasympathetic influence on basal heart rate in posttraumatic stress disorder. J Psychosom Res 2006;60:83-90.

194 ó Hartaigh B, Bosch J, Pilz S, Loerbroks A, Kleber M, Grammer T, Fischer J, Boehm B, Thomas G, Marz W: Influence of resting heart rate on mortality in patients undergoing coronary angiography (from the Ludwigshafen Risk and Cardiovascular Health [LURIC] study). Am J Cardiol 2012;110: 515-520.

195 Jensen M, Suadicani P, Hein H, Gyntelberg F: Elevated resting heart rate, physical fitness and all-cause mortality: a 16-year follow-up in the Copenhagen Male Study. Heart 2013; 99:882-887.

196 Panagioti M, Gooding P, Tarrier N: Hopelessness, defeat, and entrapment in posttraumatic stress disorder: their association with suicidal behavior and severity of depression. J Nerv Ment Dis 2012;200:676-683.

197 Sher L: Brain-derived neurotrophic factor and suicidal behavior. QJM 2011;104:455458.

198 Katon WJ, Lin EH, Von Korff M, Ciechanowski P, Ludman EJ, Young B, Peterson D, Rutter CM, McGregor M, McCulloch D: Collaborative care for patients with depression and chronic illnesses. N Engl J Med 2010;363:2611-2620. 